\title{
THE PERCEPTION OF “THE OTHER” BY THE HIGH SCHOOL STUDENTS AND THE TOLERANCE
}

\author{
Valērijs Makarevičs \\ Daugavpils University, Latvia \\ Dzintra Iliško \\ Daugavpils University, Latvia \\ Jūlija Tolmačova \\ Daugavpils University, Latvia
}

\begin{abstract}
The issue of tolerance has been actively discussed in psychology. Psychological science has to solve a number of important methodological problems related to the etiology of this term. Adolescence is the time then one's identity is being formed. This can be assumed by the authors that the pupils with a positive identity are more tolerant towards "others." The hypothesis of the study: Positive attitude influence the perception of "tolerant" schoolchildren by the "other" to a greater extent. The perception of the "other" by "intolerant" schoolchildren is more subject to negative stereotyping. For the purpose of the study, a methodology for measuring tolerance was developed. It included scales of measuring interpersonal and intergroup tolerance. In addition, expert teachers avaluation of pupils were used. Based on their assessments, two groups of pupils were formed. One of them experts rated as "good" pupils. They received higher marks on the tolerance scale. The second group of pupils, according to the experts' evaluation, had serious problems with discipline at school. They received low marks on the tolerance scale. This group of pupils was called "hooligans." The results of the study indicate that tolerant students have no significant differences in the perception of "themselves" and "strangers." The perception of "hooligans" shows a polarization effect: "they" are perceived only positively but "strangers".
\end{abstract}

Keywords: tolerance, high school students, self-esteem, friends, strangers.

\section{Introduction}

Van Dorn defines tolerance as accepting things that one disagrees with, disapproves or dislikes (Van Dorn, 2012). The author's definition of tolerance includes not only social aspect, but also an activity of a person. C. Rapp develops his definition of tolerance by taking into account the current social situation in Western Europe. He defines tolerance as one's ability to put up with something potentially difficult, such as increasing the influx of immigrants into one’s country (Rapp, 2015). 
Makarevičs et al., 2020. The Perception of "the other" by the High School Students and the Tolerance

Sometimes tolerance is related to a place in the repertoire of relations between people. T.M. Scanlon wrote that tolerance requires one to accept people and permit their practices even when one strongly disapproves them. Tolerance involves an attitude that is intermediate between wholehearted acceptance and unrestrained opposition (Scanlon, 2003). One can also find extreme definitions of tolerance as social phenomena that a person does not like or hates (MorenoRiaño, 2006)

The term tolerance is used in various spheres of human life. The authors suggest one more definition that is used in a political psychology in which competing groups support a positive orientation of actions towards each other in the field of openly conflicting values or interests (Jackman, 1977).

Tolerance as a psychological term appears in the middle of the twentieth century. It is used in relation to the situation of ambiguity in which a person is located. The term is increasingly used in a narrow sense - as a relation to the social world and other people. In the modern world, which is characterized by the processes of globalization, the problem of tolerance is of particular importance. As Vogt wrote, without tolerance, cultural diversity and peace cannot be preserved (Vogt, 1997). Tolerance in the interpersonal relationships helps to find a compromise in the debate and serves as a means to reach agreement (Vogt, 1997).

Researchers seek to identify the boundaries between tolerance and other similar manifestations of human activity. Vogt wrote that the term tolerance implies opposition or disagreement. If this is not the case, one should speak not only about tolerance, but also about indifference or simple sympathy. Tolerance is required only in the case of hostility, disagreement, disapproval, and, therefore, is closely associated with differences between people (Vogt, 1997).

As noted above, one of the directions of the study of tolerance is the study of the phenomenon of tolerance in relation to uncertainty. As noted by Furnham and Marks, the focus of interest about this phenomenon is increasingly shifting toward social, clinical, and organizational psychology, where tolerance is seen as a measure of adaptation and healthy functioning of an individual (Furnham \& Marks, 2013). McLain defined tolerance as "a range, from rejection to attraction, from reactions to stimuli perceived as unfamiliar, complex, dynamically uncertain, or subject to multiple conflicting interpretations" (McLain, 1993, p. 184). According to Frenkel-Brunswick, low tolerance for uncertainty is manifested in one's inability to see several solutions to solve a difficult situation, one's inability to perceive simultaneously the positive and negative traits of one person, a black and white outlook on life, a rigid dichotomy in evaluating events, being closed to others to gain confidence (Frenkel-Brunswick, 1951). 
For the individuals with a low tolerance for uncertainty in ambiguous situations, difficulties arise in meaning making situations. The lack of the necessary information creates fear. Fear generates stress and avoidance of contact with other people (Furnham \& Ribchester, 1995).

The representatives of positive psychology are most optimistic and argue that tolerance can be considered as a part of the positive constructs that could potentially lead to a well-being and prosperity of people and society (Linoa, Hashimb, \& Ricardoc, 2017).

Among the approaches of classifying tolerance, the following approaches can be distinguished:

- in the areas of human social activity: political, moral and social tolerance (Vogt, 1997);

- according to a degree of awareness: non-reflective tolerance characteristic to the monocultural societies, and reflective tolerance as a conscious rejection of prejudice, beliefs and discriminatory behavior in multicultural societies, to which many European countries belong to as a result of the flows of immigrants (Witenberg, 2019);

- according to the criterion of intrapersonal, interpersonal, intergroup and communication (Makarevich, 2001);

- $\quad$ by the time criterion: situational tolerance and tolerance as a quality of personality (Makarevich, 2001).

Several researchers point to the connection that exist between tolerance and a self-confidence (psychological stability) (Belasheva \& Petrova, 2016; Kozhukhar, 2013).

An extensive study of the relationship between tolerance and personal characteristics of a person was undertaken by A. Banyukhov and O. Rudykhina (Banyukhova \& Rudykhina, 2007).

They wrote that personality traits inherent in a tolerant person can have both positive and negative significance for one's life.

On the one hand, a person with a high level of tolerance is characterized by an orientation towards values of a self-actualizing personality, such as kindness, justice, and others, a desire to take into account the needs of another person, due the expressiveness of an idealistic style of thinking, as well as developed flexibility of thinking and a willingness to take responsibility for what is happening in one's life (Makarevičs \& Iliško, 2019).

On the other hand, such a person will not be sensitive to his/her own needs, he/she will have orientation towards the opinions of others, which is manifested in the low level of development of volitional qualities (Banyukhova \& Rudykhina, 2007, p. 315). 
Makarevičs et al., 2020. The Perception of "the other" by the High School Students and the Tolerance

\section{Tolerance and Education}

The relationship of education and tolerant human behavior is considered by researchers in two aspects. The first concerns how education levels affect tolerance. The second concern is how is it possible to teach tolerant behavior.

It has been written that there is a direct connection between education and tolerance (Brehm, (1998). In addition, tolerance contributes to the formation of emotional stability of a person. (Belasheva \& Petrova, 2006). As for the training of tolerance, researchers often focus on the opposite aspect: lover level of intolerance.

One of the manifestations of intolerance in adolescence and youth is ingroup favoritism. In its extreme manifestations, group favoritism is associated with the preference of "friends" and a negative attitude towards members of groups or companies of "others," which are perceived as "strangers." Consequently, one of the tasks of teaching tolerance is to overcome in-group favoritism. M. Sherif experimentally proved that this can be done by uniting groups and setting common goals for them (Sherif, 1967). However, La Barbera, who worked with the groups of Chinese immigrants and locals - Italians, showed that having common goals is not enough. This is also necessary to accept these goals as significant for each individual. This increases the level of motivation and promotes tolerant relationships (La Barbera, 2015).

\section{Tolerance and Stereotypes}

The studies on the psychology of tolerance focus on three constructs: stereotypes, prejudice, and racism (Christie and Dawes, 2001). Stereotypes are usually seen as a form of social categorization that simplifies and reduces the complexity of the social world (Brown, 1995). D. Christie and A. Dawes emphasize that stereotypes can have both positive and negative aspects (Christie \& Dawes, 2001). Unlike stereotypes, prejudice and tolerance are mutually exclusive manifestations of human activity (Van Dorn, 2012).

Stereotypes depend on the characteristics of the groups to which the individual belongs. E. Golebowska found out that tolerance is related to how well the person's behavior matches the stereotypical model of the group in which he or she is a member (Golebowska, 1999).

The influence of stereotypes on the processes of perception of other people can serve as an indicator of personality deformation, which manifests itself as an intolerant attitude towards others. When working with adolescents one needs to take into account that a search for the identity can take on negative forms, manifested in intolerance and stereotyping of others' perceptions (Makaryev, 2009). 
One of the factors that contributes to a formation of stereotypical perceptions of other people is stress (Friedland, Keinan, \& Tytiun, 1999). Formation of identity begins in adolescence. This process is often associated with stressful experiences and the use of negative stereotypes when describing peers and other people that can serve as an indicator. In the future such an attitude towards others can be fixed and manifests itself as intolerance.

\section{The Boundaries of Tolerance}

The authors refer to another definition of the boundaries of tolerance. This point of view is implicitly disclosed in J. Ferrar's dimensions of tolerance. She writes that tolerance is not a one-dimensional phenomenon. There are at least three main components of tolerance: the degree of approval or disapproval; a degree of permission or prohibition; and the origins of beliefs (investigated or unexplored). There are at least three major components of tolerance: extent of approval or disapproval, extent of permission or prohibition and the origins of belief (examined or unexamined) (Ferrar, 1976). This should be noted that the boundaries of tolerance depend on the individual (degree of approval or disapproval), on social norms and requirements set for the behavior of the subject (degree of permission or prohibition) and the source of the origin of these norms and the related beliefs (religion, traditions, culture, morality, law).

The boundaries of tolerance are problematic both in the axes of history and in geography (Boundaries of Toleration, 2014).

I. Belasheva and N. Petrova stress that tolerance is based on the acceptance (rather than rejection) of the other while maintaining the boundaries of one's individuality (Belasheva \& Petrova, 2006).

Numerous studies indicate that the manifestation of intolerance depend on cultural traditions, and the reason for this may be not only a violation by other boundaries, but also a violation of other behavioral norms accepted in his/her culture in situations that do not directly threaten the individual (Makarevičs \& Dombrovskis, 2006).

On the other hand, the boundaries of tolerance may be associated with the functioning of the personality. According to A. Banyukhova and O. Rudykhina, there is a threshold level of tolerance, which leads to deterrence of one's own interests, depending on the external assessments and circumstances, and one's inability to actively use constructive methods for resolving problem situations (Banyukhova \& Rudykhina, 2007). 
Makarevičs et al., 2020. The Perception of "the other" by the High School Students and the Tolerance

\section{Research Methods and Design}

One of the important indicators of the manifestation of tolerance intolerance is the modality of the stereotypes that the individual uses in the process of social perception of "himself/herself" and "strangers." This determined the aim of this study: to specify the stereotypes of perception of "others" and "strangers" by the group of tolerant and intolerant pupils.

The study comprises fifty secondary school pupils in the city of Daugavpils, Latvia. The age of the participants ranges from 16 to17 years. They were divided into two groups: "tolerant" and "intolerant." Teachers acted as experts in the process of selection of those groups of pupils. The children, whom the teachers described as behaving pro-socially and respectfully towards their peers, not entering into conflicts with teachers, made up the group of "tolerant" children. The children, who, according to the description of teachers, displayed aggression in relations with their peers, came into conflict with teachers, made up the group of "intolerant" pupils. Thirty people comprised the first group and twenty pupils made up the second group.

The study applied the technique called Kelly's Grid (Kelly, 1991). Kelly’s repertoire is a matrix, the columns of which are associated with certain people and their social roles, and the rows are associated with personal characteristics or the respondent's attitude to these people.

The columns of the matrix were named in the following way: me, a typical representative of the group, a typical representative of an alien group, the person I don't like (stranger), a person that I like.

The lines in the matrix point to the stereotypes. Three were positive: always help, clever, hardworking, and two negative: unreliable in business and having poor manners.

Respondents filled in the matrix, guided by the following criteria: completely agree (+3); I agree (+2); partially agree $(+1)$; I do not know (neutral position) (- 0 ); partially disagree (-1); I do not agree (-2); totally disagree (-3).

It should be noted that the matrix, which was used in the study, contained 22 columns and 20 rows. It was intended to study stereotypes associated with inter-individual, intergroup and inter-mental tolerance. In this article, the authors explores the relationship between stereotypes and interpersonal tolerance.

\section{Research results}

For the convenience of processing the obtained data, the authors transformed the above criteria in such a way as to get rid of negative values:

I completely agree (-7), I agree (-6), partially agree (-5), I don’t know (neutral position) (-4); partially disagree (-3); I do not agree (-2); completely disagree 
Proceedings of the International Scientific Conference. Volume III, May $22^{\text {th }}-23^{\text {th }}, 2020.353-363$

$(-1)$. The results obtained are presented in Tables 1 and 2 as average values for the sample.

Table 1 The results of a study of a subgroup of tolerant schoolchildren (average vsalue)

\begin{tabular}{|l|l|l|l|l|l|}
\hline Stereotypes & Me & $\begin{array}{c}\text { Typical } \\
\text { Representative } \\
\text { of my group }\end{array}$ & $\begin{array}{c}\text { Typical } \\
\text { representative } \\
\text { someone else's } \\
\text { group }\end{array}$ & $\begin{array}{c}\text { A person } \\
\text { that I like }\end{array}$ & $\begin{array}{c}\text { A person } \\
\text { that I don't } \\
\text { like }\end{array}$ \\
\hline Will always help & 4,8 & 4,9 & 4,7 & 5,1 & 3,7 \\
\hline Clever & 5,9 & 5,9 & 4,6 & 5,1 & 3,2 \\
\hline Hardworking & 5,7 & 5,5 & 4,9 & 5,8 & 3,1 \\
\hline $\begin{array}{l}\text { Unreliable in } \\
\text { business }\end{array}$ & 1,5 & 1,9 & 2,2 & 2,8 & 2,3 \\
\hline Poorly mannered & 2,6 & 2,8 & 3,0 & 2,5 & 4,2 \\
\hline
\end{tabular}

Table 2 The results of a study of a subgroup of intolerant schoolchildren (average values)

\begin{tabular}{|l|l|l|l|l|l|}
\hline Stereotypes & \multicolumn{1}{|c|}{ Me } & $\begin{array}{c}\text { Typical } \\
\text { Representative } \\
\text { of } \\
\text { my group }\end{array}$ & $\begin{array}{c}\text { Typical } \\
\text { representative } \\
\text { someone else's } \\
\text { group }\end{array}$ & $\begin{array}{c}\text { A person } \\
\text { that I like }\end{array}$ & $\begin{array}{c}\text { A person } \\
\text { that I don't } \\
\text { like }\end{array}$ \\
\hline Will always help & 4,6 & 4,7 & 4,4 & 5,2 & 4,8 \\
\hline Clever & 6,1 & 5,1 & 3,4 & 5,2 & 2,9 \\
\hline Hardworking & 6 & 5,7 & 4,8 & 5,4 & 4,1 \\
\hline $\begin{array}{l}\text { Unreliable in } \\
\text { business }\end{array}$ & 1,9 & 3,0 & 3,6 & 2,7 & 3,3 \\
\hline Poorly manered & 3,0 & 3,8 & 2,1 & 3,0 & 4,4 \\
\hline
\end{tabular}

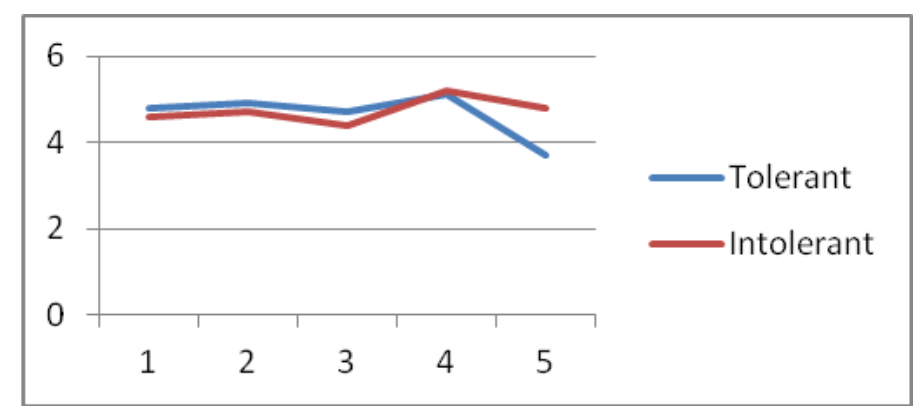

Figure 1 The average grades of tolerant and intolerant schoolchildren according to the stereotype “always help”. Mann-Whitney U-test = 11 (differences are insignificant)

Hereinafter, number 1 indicates I am the respondents, number 2 indicates a typical the representative of my company, 3 - a typical representative of a foreign company, 4 - a person who I like (my own), 5 - a person who I do not like (someone else's). 
Makarevičs et al., 2020. The Perception of "the other" by the High School Students and the Tolerance

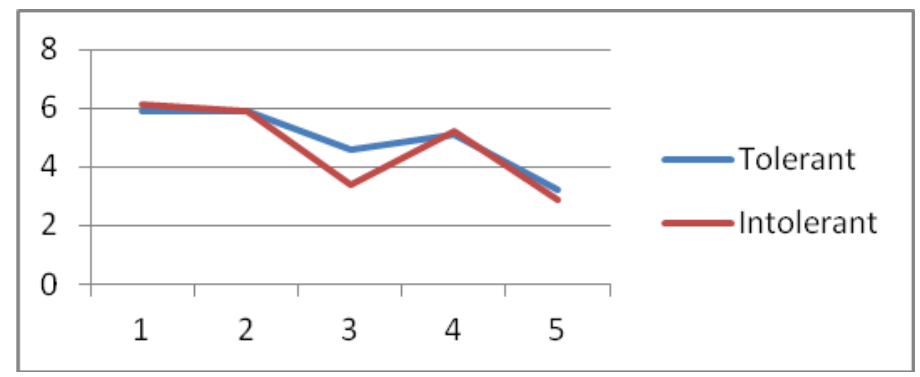

Figure 2 Average grades of tolerant and intolerant schoolchildren according to the "smart" stereotype. Mann-Whitney $U$-test $=12$ (differences are insignificant)

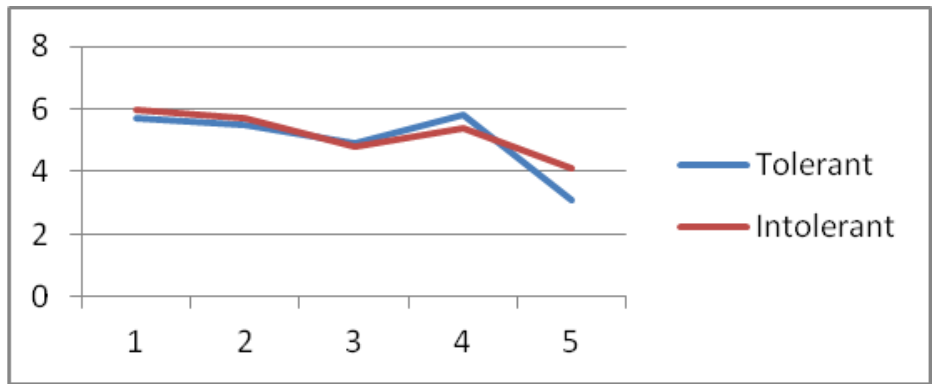

Figure 3 The average grades of tolerant and intolerant students by the stereotype of "hardworking". Mann-Whitney U-test = 12.5 (differences are insignificant)

Figures 1-3 show that the assessments in the field of positive stereotypes of tolerant and intolerant students are either close or coincide. The exception is the role positions "typical representative of a foreign company" and "a person who I do not like." In the first case, there is a tendency that tolerant typical representatives of a foreign company are evaluated more positively than intolerant. In the second case (the person I don't like), the ratings of intolerant students turned out to be more positive than the ratings of tolerant students. But, according to the Mann - Whitney criterion U calculated for these cases, these differences are not statistically significant.

The authors also considered the distribution of respondents' assessments in the field of negative stereotypes.

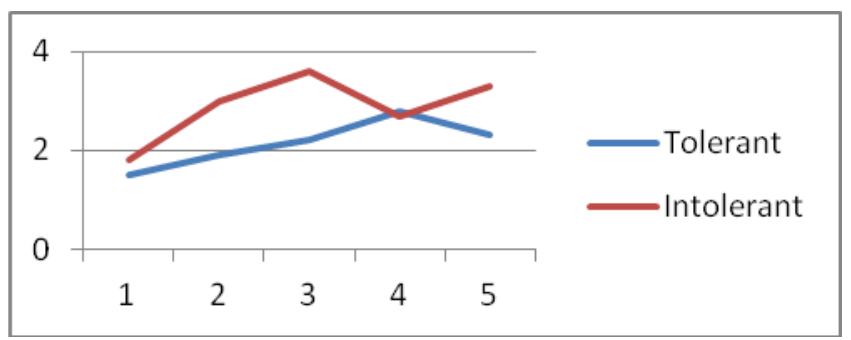

Figure 4 The average grades of tolerant and intolerant students by the stereotype of "unreliable in business". Mann-Whitney U-test = 4

(differences are significant at the level of 0.05) 


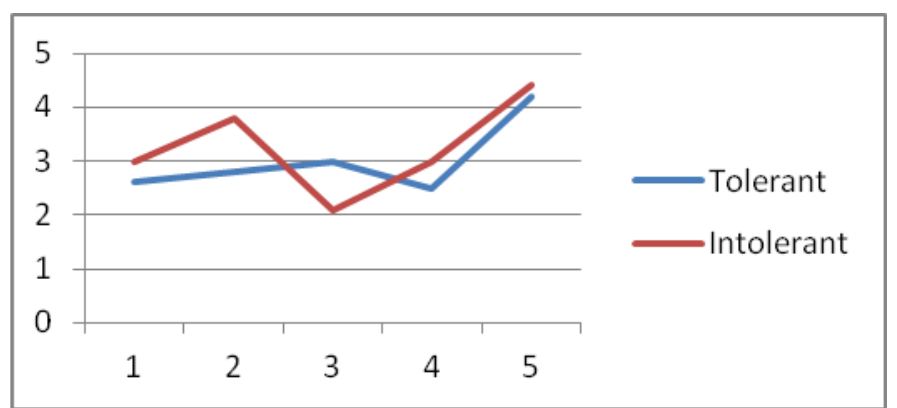

Figure 5 The average grades of tolerant and intolerant students by the stereotype of "poorly educated." Mann-Whitney U-test = 9 (insignificant differences)

Figure 4 shows that significant differences firstly appear here. The most intolerant students by the stereotype of "unreliable in business" are typical representatives of someone else's company and people whom I do not like.

Figure 5 shows that the stereotype "poorly educated" received a higher average score among the tolerant students in relation to the role position "typical representative of another group.” This difference is not statistically significant.

The role position of "poorly educated" tolerant and intolerant students is assessed equally negatively. It can be seen from the figures that our assumption about the connection between tolerance and stereotypes was only partially confirmed.

Among the reasons that influenced the result, the authors observed the following.

The level of education affects manifestations of tolerance. The study involved respondents who attended high school. Consequently, there was a selection during the transition from primary to the secondary stage of schooling. The criterion for intolerance here may be described as offensive nicknames that the students received in the primary school.

\section{Conclusions}

A sign of intolerant behavior may be described as the desire for selfassertion, which is normal in adolescence. In this regard, this is necessary to specify the criteria for intolerant behavior in relation to the age characteristics.

The results obtained in this study suggest that among the stereotypes that guide pupils in their social perception of other people, there are subjectively insignificant and significant stereotypes. In this study, the most significant for the respondents was the negative stereotype of "unreliable person," which corresponds to the desire of representatives of this age to find reliable friends and, having received confirmation of reliability, to strengthen their ego identity. 
Makarevičs et al., 2020. The Perception of "the other" by the High School Students and the Tolerance

\section{References}

Banyukhova, A.E., \& Rudykhina, O.V. (2007). The relationship of tolerance with personality traits and its boundaries. Tolerance and intolerance in modern society: discrimination. Materials of the International Scientific-Practical Conference. St. Petersburg: St. Petersburg State University, 311-316.

Belasheva, I., \& Petrova, N. (2016). Psychological stability of a personality and capability of tolerant interaction as diverse manifestations of tolerance International Journal of Environmental and Science Education, 11(10), 3367-3384.

Brehm, C. (1998). Stereotypes, Tolerance, and the Classroom. Retrieved from http://citeseerx.ist.psu.edu/viewdoc/download?doi=10.1.1.850.5360\&rep=rep1\&type=p df (17.12.2019).

Brown, R. (1995). Prejudice: Its Social Psychology. Cambridge, MA: Blackwell.

Christie, D.J., \& Dawes, A. (2001). Tolerance and Solidarity. Peace and Conflict: Journal of Peace Psychology, 7(2), 131-142.

Ferrar, J.W. (1976). The dimensions of tolerance. The Pacific Sociological Review, 19(1), 63-81. Doi: 10.2307/1388742.

Frenkel-Brunswick, E. (1951). Personality theory and perception. In R. Blake, \& E. Ramsey (Eds.), Perception: An approach to personality. (pp. 23-34) New York: Ronald. Doi: 10.1037/11505-013

Friedland, N., Keinan, G., \& Tytiun, T. (1999). The effect of psychological stress and tolerance of ambiguity on stereotypic attributions. Anxiety, Stress \& Coping: An International Journal, 12(4), 397-410. Doi: 10.1080/10615809908249318

Furnham, A., \& Ribchester, T. (1995). Tolerance of ambiguity: A review of the concept, its measurement and applications. Current Psychology, 14, 179-199. Doi: 10.1007/BF02686907

Furnham, A., \& Marks, J. (2013). Tolerance of Ambiguity: A Review of the Recent Literature. Psychology, 4(9), 717-728. Retrieved from https://www.scirp.org/pdf/ PSYCH_2013091613521890.pdf (10.11.2019).

Golebowska, E. (1999). Gender gap in political tolerance. Political Behavior, 25(1), 43-66.

Kelly, G.A. (1991). The Psychology of Personal Constructs. A theory of personality. London: Routledge.

Kozhukhar, G. (2013). Basic assumptions as predictors of interpersonal tolerance and ethnic identity in psychology. The 5th Congress of Russian Psychological Society. Procedia Social and Behavioral Sciences, 86, 511 - 517.

La Barbera, F. (2015). Research reports educating to tolerance: Effects of communicating social psychology. Research findings. Europe's Journal of Psychology, 11(3), 476-483. Doi: 10.5964/ejop.v11i3.888.

Linoa, M., Hashimb, I., \& Ricardoc, R. (2017). The Conceptualization and operationalization of cultural tolerance: Adopting positive psychology perspective. Social Sciences Postgraduate International Seminar (SSPIS) 2017. School of Social Sciences, USM, Pulau Pinang, Malaysia, 213-220.

Makarevičs, V., \& Dombrovskis, V. (2006). Migration und tolerance. Migration in Europa: Soziologische und psihologische forschungen, 159-176, Kiev.

Makarevich, V. (2001). Tolerance as a psichological problem. Tolerance un citas psihologidkās un pedagogisiskās problēmas, (29-38). Daugavpils: Saule. 
Makarevičs, V., \& Iliško, Dz. (2019). Governance of informal learning as a pathway for the development of young adults' agency for sustainability. In Calvo de Mora, J., \& Kerry J. Kennedy (Eds.), Schools and informal learning in a knowledge-based world. Routledge: Taylor and Francis. Doi: https://doi.org/10.4324/9780429022616

Makaryev, I.S. (2009). Intolerance as a form of manifestation of a teenager's personality deformation. Tolerance and intolerance in modern society. Materials of the International Scientific-Practical Conference, 327-334. Saint Petersburg: St. Petersburg State University, 327-334.

McLain, D.L. (1993). The MSTAT-I: A new measure of an individual's tolerance for ambiguity. Educational and Psychological Measurement, 53, 183-189. Doi: 10.1177/0013164493053001020

Moreno-Riaño, G. (2006). Tolerance, identity, and the problem of citizenship. Gerson Moreno-Riaño (Ed.), Tolerance in the twenty - first century: Prospect and challenges, (pp. 81-96). London: Lexington books.

Rapp, C. (2015). More diversity, less tolerance? The effect of type of cultural diversity on the erosion of tolerance in Swiss municipalities. Ethnic and Racial Studies, 38(10), 1779-1797.

RJackman, M. (1977). Prejudice, tolerance, and attitudes toward ethnic groups. Social Science Research, 6(2), 145-169.

Stepan, A., \& Taylor, C. (Eds.). Boundaries of Toleration. New York: Columbia University Press.

Scanlon, T.M. (2003). The Difficulty of Tolerance. Cambridge University Press, Cambrige.

Sherif, M. (1967). Social Interaction: Process and Products. New York. Routledge.

Van Doorn, M. (2012). Tolerance. Retrieved from http://www.sagepub.net/isa/ resources/pdf/Tolerance.pdf

Vogt, W.P. (1997). Tolerance and Education: Learning to Live with Diversity and Difference. London: Sage.

Witenberg, R.T. (2019). Psychology of Tolerance. Conception and Development. Springer, Verlag. 